\title{
Note From the EDitorial BoARD
}

After ten years, T.M.C. ASSER PRESS and the European Constitutional Law Review have decided to go their own separate ways.

The editorial board of EuConst wants to express its immense gratitude to ASSER PRESS for all that it has done for the review and especially to Philip van Tongeren, the publisher who is co-responsible for the birth of the review and who played an important role in its success.

We also thank Marjolijn Bastiaans, Antoinette Wessels and Wilma Wildeman for all their years of intensive, enthusiastic and fruitful cooperation, and Nettie Dekker and Henri de Bie for their fine copy-editing and type-setting.

We finally thank Ernst Hirsch Ballin, the president of ASSER, and Edgar du Perron, the dean of the Law Faculty of the University of Amsterdam, for their generosity to let us go our own way with the review.

We will continue to publish EuConst independently with CAMBRIDGE UNIVERSITY PRESS. We have faith in the loyalty of our readers and authors. We call on them to provide continued support by submitting excellent manuscripts in the broad field of European constitutional law, and by taking out personal subscriptions or convincing the institutions to which they are affiliated to take out institutional subscriptions, so that the future of EuConst can be guaranteed.

On behalf of the whole editorial board, the editors-in-chief,

Leonard Besselink Monica Claes Jan-Herman Reestman 